\title{
Learning through Senses in Geography, Evaluation and Opportunities
}

\author{
PhD. Jostina Dhimitri \\ Department of Geography, Faculty of History and Philology, \\ University of Tirana \\ jostinak@yahoo.com \\ Associate Professor Albina Sinani \\ Department of Geography, Faculty of Education and Social Sciences \\ University "Eqrem Cabej" Gjirokastra \\ sinanialbina@yahoo.com
}

\section{Doi:10.5901/jesr.2013.v3n7p671}

\section{Abstract}

Knowledge through senses is the first source of any recognition. Realized through senses and perceptions, it changes by age and individuals. It plays an irreplaceable role in the learning process. It is works together with logic recognizing accompanying and fulfilling the learning to each individual. In the paper there are presented the change that is gained during age growth versus sensory recognition. Also we are trying to treat different ways of realization of sensory knowledge in the subject of geography in different cycles of education. In the paper it is estimated the use of different teaching tools, their possibilities, discussed in a case study. It analyzed the text: "Geography 11", which is in use in our schools. The methodology used is explanatory, analysis, focusing on explaining the process of learning through senses. Statistical methods come in assistance of further analysis.

Keywords: learning through senses, geography, learning process, students.

\section{Introduction}

The paper has as object "learning through senses", treated as the initial element in the learning process. In this paper it is treated too, the logical recognition, as a psychological basic component of the thinking, as well as the various activities that we combined it. Another issue is addressed the different ways of realization of sensory knowledge in the subject of geography, relying on different cycles of pre-university education system and at various stages of the individual, as in the early school age and adolescence. The performance of sensory recognition is analyzed through text "Geography 11" with authors Doka Dh.and Draci B., text used in our schools in pre-university education. This is accomplished by various element presented in the text such as images, photographs, maps etc.

\section{Methodology}

The used methodology is that analytical and explanatory - illustration. These methods are used with a view to explaining the process of learning through sensory recognition. Through the use of theoretical materials is made possible explanation, illustration of the issues dealt below. Is made viable the explanation of the various ways of obtaining the sensory recognition in the subject of geography, focusing on text "Geography 11".

\section{Recognition and logical sense as the primary element in the learning process}

Sensory recognition is a direct reflection of objective reality, and Gaçe $\mathrm{P},(1988)$ cites that it is primary source of every recognition. Sensory recognition is performed using sensibility, perception and imagination. It differs in certain age groups and individuals, being conditioned by external and internal factors. It plays a primary role in the learning process. During the learning process the sensory level of recognition combined with logical level of recognition by the accompanying pupils throughout this process.

To students of new school age, in the process of learning, the sensory recognition occupies a significant place 
because of the prevalence of the first signaling system. Students gain knowledge through contact and direct action with objects, with different figures and their appearance. "Learning through looking" is seen as a fundamental and valuable skill, increasingly relevant in a world dominated by visual communication. (Learning through looking: Icknield High school, June 2011, pg.2). In this age there exist elements of logical recognition.

Through sensory recognition pupils recognize the properties and external qualities of objects and phenomena by removing the internal core. Such knowledge is superficial and often leads to students erroneous conclusions. (e.g.: for children of the early school age Earth is not orbiting the Sun, but the Sun is one that revolves around the Earth). Thus it becomes necessary clarifications and corrections performed by sensory recognition combined with elements of logical knowledge. Pupils should be able to see, to hear, and to separate the important part of the items and objects.

At the age of adolescence and then sensory recognition receives new features under the influence of learning and as a result of the vigorous development of other psychological cognitive processes. The amount of errors during sensory recognition in the process of learning falters and the amount of exact material increases.

The survey is the highest form, most active and complex of perception. Gace $\mathrm{P},(1988)$ states: "The survey is closely related to mental actions, such as analysis, synthesis, comparison, classification, etc."

Width, accuracy and depth of sensory recognition in learning process depends not only on the use of resources of materialization, but also by making use of more and more instruments, various technical tools, which complement the sensory organs, empower them and increase their perceptual skills.

Tools such as various maps, pictures of different images of objects and geographical phenomena, facilitate the process of perception by pupils and students. Sensory recognition is necessary at all levels of learning in school. However, students will need more in-depth information which does not give the senses. So logical recognition helps thinking process by which the pupils discovers the true cause of these objects and phenomena, the essence and laws of their development.

At the new school age the thinking undergoes marked changes. Pupils begin to learn at school having concrete thinking, while under the influence of learning, they gradually pass from the external side recognition of objects and phenomena in recognition of their essence. The highest rate of thinking in the school age is theoretical thinking, which created the opportunity for predictions. In this age it is not yet formed ability to difference features and properties and to distinguish the essential.

The level of acquisition by students of knowledge depends on the level of development of mental activities. At the new school age, especially in its beginnings, analytic-synthetic activity is still quite original. Its development goes by practical actions at the sensory and mental actions later on.Analytical activity of pupils passes from the practical analysis, in that mental-abstract, from partly analysis, in that complex and systematic. Also at the new school age it is developed synthesis and comparison.

The surveys of the learning process show that the new pupils school age encounter difficulties in establishing the connections and understanding of addiction causation. In this age and later the students have to pass easily from cause to effect rather than the effect to cause. The effectiveness of the acquisition of knowledge by students is strongly correlated especially with their general strength. Basis for generalization are reached by analysis, synthesis and comparison.

In recent years the new school age students gain agility to analyze, synthesize and compare to some extent independently.

At the age of adolescence marked changes occur in the development of thinking. Even at this early age, the impact of concrete-visual components of thinking becomes organized and run. One characteristic is the apparent development of critical thinking. At the age of adolescence, the student is not inclined to blindly rely only on the authority of teachers or text and he wants to have its opinions and views and the start to keep its critical attention. Another important characteristic at this age is also incrementally formation of the active, independent and creative thinking. In distinction from adolescence to adulthood school age, the critical thinking is developing in the rapid and visible content. He becomes directed and controlled. The ability of students to self-control, self-instruction, self-assessment, to estimate and to control the others in perfected link in the link.

\section{Some ways of realization of sensory recognition in the subject of geography through learning materials}

Developments in technology, new teaching techniques, and various instruments have grown possibility of an effective teaching in schools.

Teaching tools form part of didactic basis, the functions of which are: 
1. Recognition function, realized by moving from concrete recognition to abstract recognition creating sustainable concepts.

2. Didactic function consists precisely in the assistance they provide for the acquisition of knowledge as systematic and consistent.

3. Motivational function that consists in increasing the interest of students to illustrate the theme of the resort suitable for the materialization.

The purpose of their use is much more activation of analyzer during observation, but also the involvement of as many senses to create to students as many specific images for a sustainable appropriation of knowledge, skills and habits.

In their studies Trandafilli \& Karaguni, (2008, p.106), conclude that the human memory registers by:

\begin{tabular}{|l|l|}
\hline Reading & $10 \%$ of the material \\
\hline Listening & $20 \%$ of the material \\
\hline Looking & $30 \%$ of the material \\
\hline Looking and listening & $40 \%$ of the material \\
\hline Individual solutions & $70 \%$ of the material \\
\hline Selfaction & $90 \%$ of the material \\
\hline
\end{tabular}

Also in another study by Terri L. White, he noted that "Experts agree that most people retain approximately:

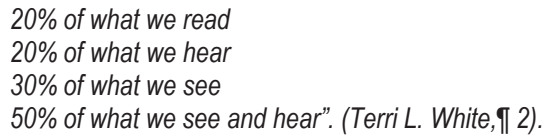

Thus we see how important learning through the senses and use and their combinations is.

Ratings for teaching materials in geography are numerous but preferably grouped into: text materials, iconic materials, mapping materials, graphical materials and quantitative measuring instruments group. Will stop at the first three related to the analysis of text "Geography 11".

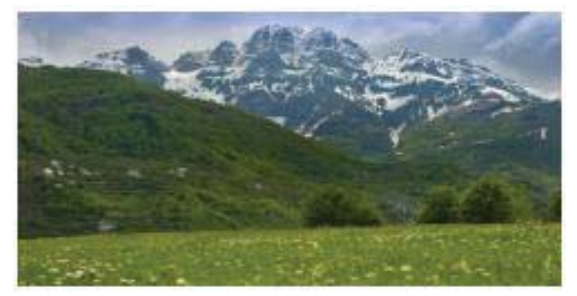

Fig.1

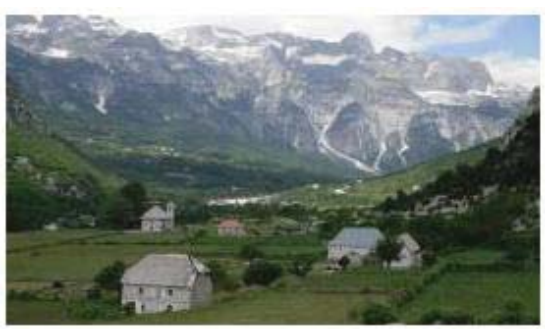

Fig.2 


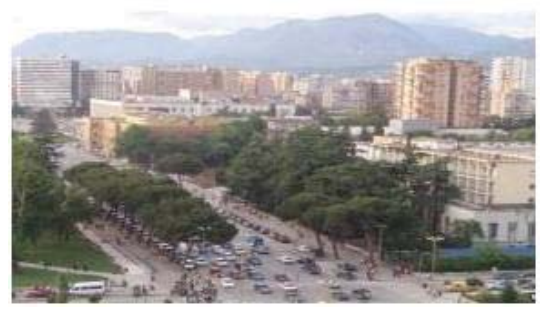

Fig.3

- Text materials include written materials. Their diversity in geography is great and aims to create to students the concrete ideas, comparisons opportunities, synthesis and analysis forming the further individual.

- Iconic materials. They are static or dynamic. They can be many e.g.: picture:

- Natural landscapes (mountains, plains, seaside etc.)

Through these pictures the students have easy and clear to understand what it is explained and also to remember better. (fig.1)

- $\quad$ Anthropological landscapes (towns, villages, industrial areas, tourist areas) (fig.2,3)

- $\quad$ Other themes (transport, trade, development, environment), (fig.4,5)

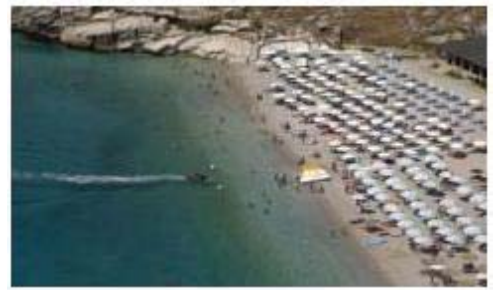

Fig.4

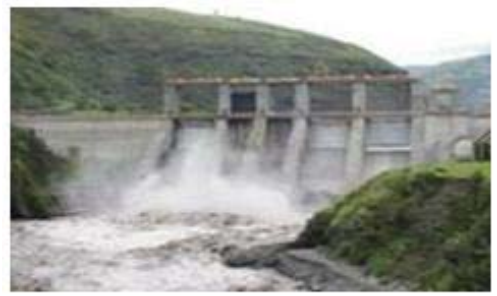

Fig.5

- Illustrative dynamic materials. These materials are part of the iconic materials including films, but not only didactic, but also documentary films and even artistic. Effective use would be in explaining phenomena such as earthquakes and volcanoes.

- Photographs and images. Photographs and images are classified different types of: pictures, hand figure, or text books.

- Mental maps. These maps serve to pupils for an efficient conception of space, especially with regard to exact localization of geographical objects. The importance of the acquisition of skills and abilities of presentation of mental maps consists in fact of the exercising of the students to observe, to mentally organize what directly or indirectly observe, to maintain the distances of relative positions, to the reference points in the service of a mental accurate, complete and correct representation.(fig.6) 


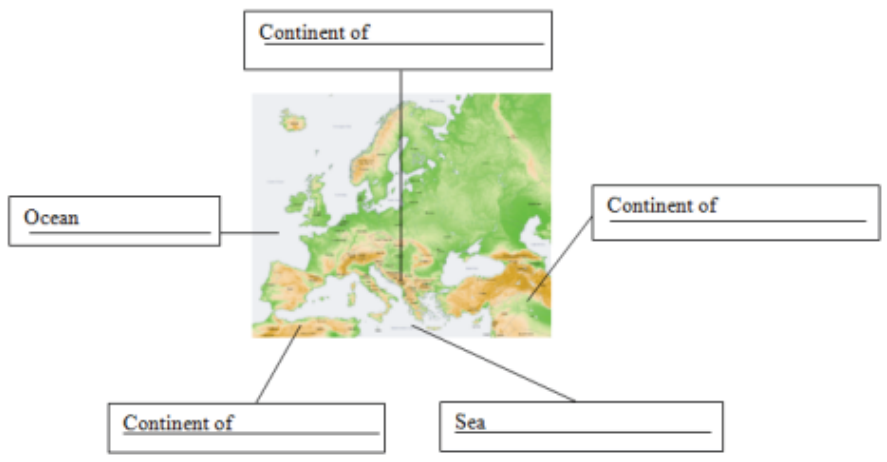

Fig 6.

- Mapping materials. Maps are used widely as didactic resources in learning geography. The map is basic didactic element of geography. The development of geographical thinking is realized through maps, so emerges the importance of learning the geography through mapping, recognition of its deep, gradually equipping students with the skills and theoretical knowledge and practical skills in the use of the map. General geographic maps. They are essential for the recognition of space, through a series of conventional signs and symbols including all physical elements such as natural and human. Thematic maps. Importance of these maps lies in the fact that: allow dealing with various problems and also allowing students to realize their original work on certain topics. This kind of thematic map can be constructed by the pupils themselves having relevant data. (fig.7)

- Graphical materials. Chart takes the attention of students and let linger in their memory. This category allows reading and immediate understanding of phenomena and presented facts. Graphics can be linear, histogram, aerogram etc.

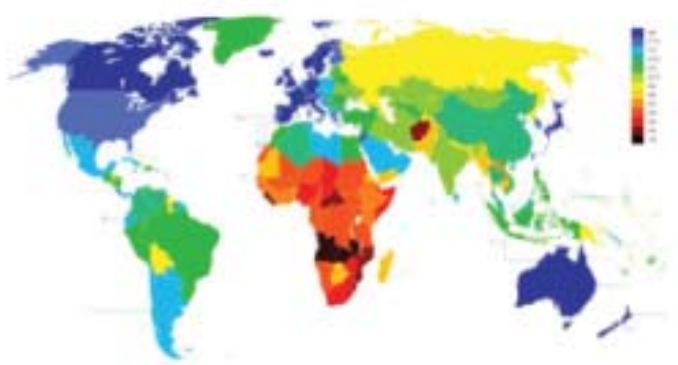

The linear chart shows dynamics of a phenomenon or occurrence. In these types of diagrams data is given before in a table and after they are reflected in chart. e.g.: Natural growth chart in Shijaku town for period 1990-2005. (tab.1, fig.8)

Tab.1

\begin{tabular}{|c|c|c|c|}
\hline Years & $\begin{array}{c}\text { Births } \\
\text { Seria 1 }\end{array}$ & $\begin{array}{c}\text { Deaths } \\
\text { Seria 2 }\end{array}$ & $\begin{array}{c}\text { Natyror growth } \\
\text { Seria 3 }\end{array}$ \\
\hline 1990 & 135 & 64 & 71 \\
\hline 1995 & 120 & 61 & 59 \\
\hline 2000 & 110 & 50 & 60 \\
\hline 2005 & 74 & 64 & 10 \\
\hline
\end{tabular}




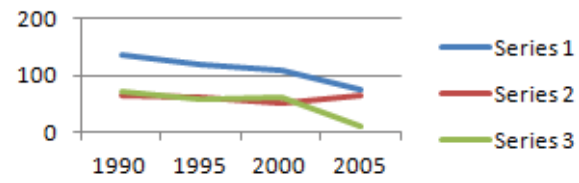

Fig.8

This chart allows understanding performance of some demographic indicators such as the number of births and deaths and natural increase. Pupils have very easily visually to show the progress of these indicators.

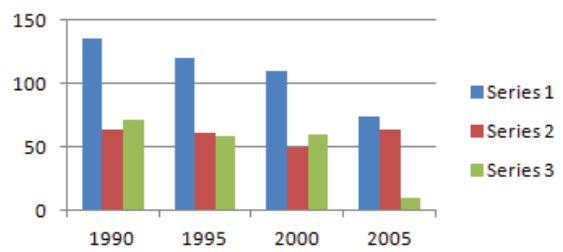

Fig. 9

Histogram shows us the data of the table but in another form of graphic. (Fig.9)

Drawings and sketches Their task is the exact appearance of reality, space, objects, and phenomena. Drawings and sketches reproduce the reduced reality and evidence that what is most important

- Quantitative materials. Statistics is a tool that allows the summary of facts quantitatively. They can be obtained from various publications of different institutions.

5. Realization of sensory recognition through text "Geography 11 " with author B. Draci and Dh. Doka, used in secondary schools of pre-university education

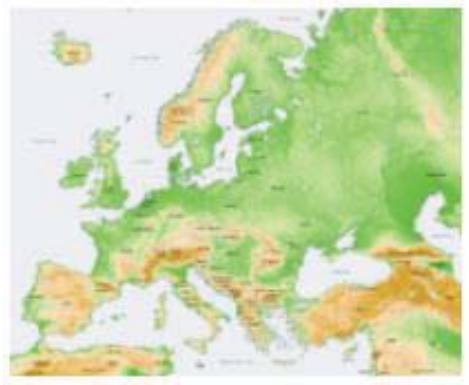

In the subject of geography there are different ways of realization of sensory recognition. One way is the realization of sensory recognition by looking. This approach can be accomplished by working with text, with map, dumb map, so to work with what we see.

Working with the map and the dumb map, text can be implemented individually or in groups. (On page 22 in text of Geography 11). Looking this map, pupils can understand the theme that will be explained; also they can give easier their opinions on the European continent by physical-geographical perspective.

Realization of sensory recognition in the text "Geography 11" through looking can also be achieved by photographic sources. Students see different pictures presented in the text and then they start to discuss about their content and meaning, and each student or group arrives at different or the same conclusions.

This is one of the many photos that are part of the text (pg. 75). Just watching that students are able to understand that it has to address the topic of world religions. (fig.10) 


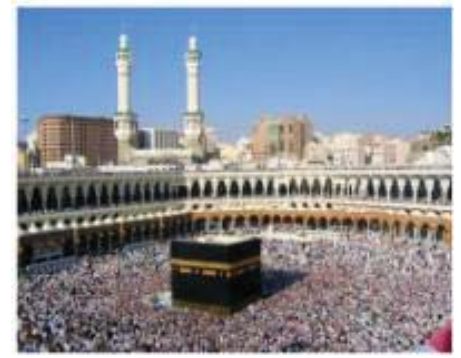

Fig.10

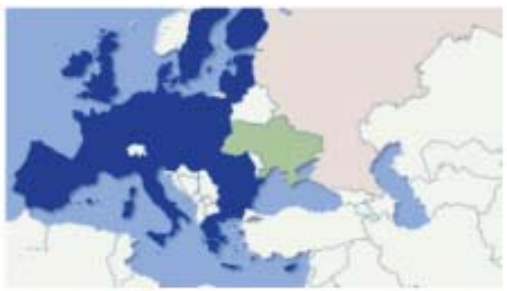

This is another map that is in the text "Geography 11" (pg. 31). It is presented on the topic for the European Union and look through it, pupils can clearly determine that countries are members and non-members of EU.

Another sense to realize the process of learning is by touching. This way of achievement of sensory recognizing can be used in 3D maps or in determining the type of the rocks. E.g.: Teacher presents a model of relief to students, by touching areas they will differ, hills and mountains. So it is a very simple process through which students understand more about what they need to know.

Also students are able to distinguish and indicate the type of component rocks in a certain region when these samples are present during lessons by looking and touching. In this case it is easy to distinguish sedimentary rocks (sandstone), which are loamy and magmatic rocks, which are solid.

Another way of achievement of sensory recognizing in the use of text "Geography 11 " is that of listening. This approach can be realized by using questions and answers. Students listen to a question, comment, argument, etc. and then manage to give an answer or reach a conclusion. This can be realized in an individually manner or in groups, depending on the object to be discussed.

Independent works can be realized in text including all the methods mentioned above, each of them at various stages and at specific research work.

\subsection{Evidence of sensory recognition in the text: "Geography 11"}

In the text: "Geography 11", there is counted the use of various teaching materials and it is shown their usage ratio to the total topics. Here they are:

- Text materials are used 6 (in 26 new topics, estimated 0.23 materials per topics)

- Iconic materials are used 20 (estimated 0.8 materials per topics)

- Photographs and images are used 3 (estimated 0.12 materials per topics)

- Cartographic materials:

a. General geographic maps are used 12 (0.5 materials per topics).

b. Thematic maps are 10 (0.4 materials per topics).

- Mental maps are used 2 (0.08 materials per topics).

- Chart is 1 (liner chart) (0.04 materials per topics). No use of histogram, aerogram and quantitative materials in the text.

There is no requirement to use a type of material or another, but their use is evaluated against to topics of geography subject program by the authors. 


\section{Conclusions}

- Sensory recognition is primary important element in the learning process. Special place is given to the logic recognition, whose importance goes parallel to the sensory recognition.

- The different ways of realization of sensory recognition, create such a complex activity that gives a very large auxiliary, creating facilities during the learning process for students as well as for teachers.

- In text "Geography 11" with author Dh.Doka and B.Draci, sensory recognition is achieved through various methods and learning material, which are used during the development of the learning process, during various topics.

- Use as many instruments that come and help us by strengthening the sense recognition, increase their perceptual skills.

\section{References}

P. Gace, "Te mesuarit e sotem dhe psikologjia pedagogjike." 1988, Tirane, fq. 104-125, Shtypshkronja "8 Nëntori".

G.Trandafili, M.Karaguni, "Didaktika e Gjeografise." 2008, fq. 101-114, IDEART.

B.Draci, Dh.Doka, "Gjeografia 11."

www.mapsofworld.com

http://www.ofsted.gov.uk/resources/good-practice-resource-learning-through-looking-icknield-high-school

http://koinonia-all.org/homeschool/learnstyles.htm

http://enlivenedlearning.com/tag/learning-through-the-senses/

http://www.teachingexpertise.com/articles/kva-how-children-learn-621

http://www.ourmontessorihome.com/discovering-montessori/what-is-the-montessori-method/ 